\title{
Study of Asset Appraisal in Merger, Acquisition and Re-organization Dongqi Zhao ${ }^{1}$ \\ ${ }^{1}$ Zhejiang Gongshang University, School of Counting, Hang Zhou, Zhe Jiang, 310018 hunter2011@foxmail.com
}

\author{
Keywords: Asset Appraisal, Merge; Economy Problems; Countermeasures
}

\begin{abstract}
Along with foundation of market economy and development of joint-stock economy, there are lots of merger, acquisition and reorganization in China enterprises. It has great effect in adjusting existing social resources, optimizing industry structure, improving efficiency of resources collocation and helping China enterprises jointing in global economy. This paper studies the method of merge and the problems in enterprise acqusition. At last, the countermeasures we should take to figure out those problems are also been studied.
\end{abstract}

\section{Introduction}

The reorganization of assets is accompanied by China's economic growth mode, adjust the economic structure and the development of state-owned strategic reorganization and the securities market, in around 1995 began to arise. From then to now, China's asset restructuring wave after wave. Said the reorganization of assets is simply the reconfiguration of corporate resources, by merger, consolidation, acquisition, sale, replacement and other ways to achieve re-selection and combination of assets subject to optimize the capital structure of enterprises, improve the overall quality of corporate assets, and ultimately build more strong position in the market organization system assets. Between different enterprises through asset restructuring or the same kinds of internal economic resources for mutual adjustment and changing the maximum value of assets in line with the purpose of industrial capital, financial capital, regroup equity capital and intangible capital, it is the business including material resources, human generalized asset resources, organizational resources reconfiguration is a comprehensive and diversified system engineering.

And the reorganization of assets is not the same, M \& A (Merger \& Acquisition, often abbreviated as "M \& A") is parked to goods, including mergers and acquisitions, means the two concepts, their common feature is to gain control of the target company. Merger means more than two companies combined into one company, the rights and obligations of the original company (or new) by the surviving company to bear. Merger, there are two situations: First, the merger (Consolidation Merger), refers to the merger of the two companies in the end of one, the other surviving down, also known as the merger; but new merger (Statutory Merger), refers to the combined the two companies are gone, and the birth of a new enterprise. In contrast, the acquisition means to obtain specific property ownership behavior. By this behavior, the party has made or acquired an asset, especially a substantial ownership. The acquisition of two ways: First, asset acquisition (Asset Acquisition); the other is the acquisition of shares (Stock Acquisition), but not necessarily all of the assets held by the seller and the shares may be only a part of it.

\section{Corporate Mergers and Acquisitions in the Asset Valuation}

In corporate mergers and acquisitions often involve the transfer of all or part of the enterprise property rights, and therefore the value of the transferred assets objective, fair and neutral evaluation is particularly important.

The Role of Asset Valuation in Corporate Mergers and Acquisitions. Asset transfer price should be based on asset valuation basis and the basis in the scientific, fair, and objective environment, to be determined through consultations. Through asset evaluation, you can find out the asset structure and operating conditions of the acquired companies, to assess the value of assets restructuring, analysis of the acquired company's future profitability and asset management 
capabilities, thereby providing reliable scientific basis for decision-making mergers and acquisitions.

Asset valuation in the investigation, assessment, analysis of the process, can be found in the merged enterprise asset management loopholes and problems on the timely analysis of the reasons, a clear responsibility to be held accountable, if necessary, it can prevent the acquisition of unwarranted loss of corporate assets, and It could be a good start for M \& A business development.

Asset evaluation not only of the physical assets of the acquired company to clean up, but also assessed its function and the value of assets. M \& A business to business assets of the acquired scientific analysis capabilities and research to promote the efficient use of assets function, improve asset utilization.

Asset valuation is a professional and strong, wide range of integrated business work, it is not only for the acquired company's assets qualitative analysis, and also the use of scientific methods was analyzed quantitatively, and give a reasonable assessment and valuation, thereby promoting the mergers and acquisitions work in quantitative, standardized, avoiding subjective and arbitrary.

Mergers and Acquisitions in the Asset Appraisal Procedures. Assets assessment procedures means assessment bodies evaluated from project commissioned until completion of the assessment project, the establishment of all the work processes and procedures project files ended. Mergers and acquisitions in the assessment of the procedure as a whole business or individual assets generally have the following main elements:

A comprehensive list of potential M \& A target; 2, to collect information on each potential mergers and acquisitions subject; 3 , from various angles corporate strategy, finance, management, etc., a comprehensive analysis of the specific circumstances of each potential merger and reorganization of the object and make comparison; 4, mergers and acquisitions to determine the object; 5 , to declare the project: specifically refers to the process of state-owned assets occupy asset unit project application assessment. Including project application, project, commissioned to assess three steps. Assets of state-owned assets outside the scope of the assessment is not required to declare the project; 6, a clear evaluation purposes, assessing the object and scope; 7, assets evaluation business consignment agreement signed; 8, the valuation date is selected; 9, develop assessment programs; 10 , guide property owner unit inventory, reporting assets, ready to collect data; 11 , checks to verify assets, verify information; 12 , detection and identification of assets; 13 , choose assessment methods and formulas; 14 were assessed against specific target estimate; 15 analysis to determine assessment, writing assessment notes; 16, aggregate asset valuation report prepared, pooled asset evaluation worksheet; 17 internal audit testing and evaluation, the results of the assessment mechanism; 18, to submit asset evaluation report, in accordance with regulations to submit relevant materials; 19, verification Confirmation: evaluation report of assets belonging to state-owned assets within the scope of the assessment must be reported to the state-owned assets management department to confirm the results of asset evaluation, state-owned assets department audited, verification, validation, asset assessment and issued a notice of confirmation. Does not require the state-owned assets management department of assets outside the scope of the assessment of state-owned assets be verified to confirm; 20, establishing project files.

China's "state-owned assets assessment management approach" Article 23: basic methods to assess the state-owned assets, including the replacement cost method, the current market price method, the income approach and the liquidation price method. Other assessment methods are derived from several methods out.

Replacement cost method. Replacement cost method, also known as the cost method is a method in assets evaluation, according to the assets being evaluated now deduct the full replacement cost of the loss of value to be evaluated to determine the method of asset prices.

(1) Direct method: cost of asset composition to the prevailing market price as the standard, were calculated for each part of the assets being evaluated price, and then find a way to add and replacement cost of the assets being evaluated.

(2) Function value method: refers to selection with the same or similar assets, asset valuation as a reference to the value of assets on the basis of reference, with reference to the assets being 
evaluated assets comparison function as the basis to calculate the assets being evaluated weight one way home costs. The formula is:

Replacement cost $=$ reference replacement cost of assets is evaluated assets $\times$ annual/annual reference

(3) The price index method: On the basis of the original cost of the asset, the asset price index by comparing the current price index and asset acquisition or construction phase when determining the replacement cost of assets is a method of assessment.

At present, in the evaluation method selection to replacement cost method is preferred, the importance of the replacement cost method also make use of research and assess the world this method has a higher level, and played in the individual asset assessment good effect. But in their overall asset valuation, replacement cost method is only for a single identifiable assets are assessed individually assessed companies, without considering it as an organic combination of assets overall profitability, but also ignores the value of the enterprise goodwill , making it a lot of deficiencies. In general, when the market approach and income method is not applicable for the cost method, the problems will appear. Stories from mergers and acquisitions have taken place on China's stock market point of view, such as mergers and Lu Ying electronic Tsinghua Tongfang, fashion industry mergers and new share Mou, Wuxi, Shanghai Volkswagen Volkswagen merger, acquisition of Shandong Linyi Karon Jiangquan Industrial Building Ceramics Co., Ltd. part of Quality assets, when the assets of the merged enterprise as a whole to assess the replacement cost method adopted almost all (Individual assets using the prevailing market price method), without using the income approach, which is internationally accepted as a whole benefits when companies use to assess the present value of customary law is not consistent.

\section{Our Asset Appraisal Industry Situation and Problems}

Current Situation of Asset Evaluation. Asset assessment is the commodity economy develops to a certain stage of the product. In 1868, the Royal Institution of Chartered Surveyors Association was established, marking the formation of asset valuation as a professional industry. At the same time, the United States, Australia, Canada and other countries are also the rapid development of asset evaluation industry, industry associations have been established throughout the assessment industry guidelines, eligibility criteria of professional appraisers, appraisers code of ethics and practice inspection and disciplinary procedures and other management systems. In the eighties of this century, the developing countries have begun to pay attention to the important role in economic development asset evaluation, and gradually standardize and develop the asset appraisal industry. Correspondingly, assets evaluation in the market economy has become increasingly important, particularly asset valuation to reflect the fair market value of the assets of this function is more and more attention. Such as Denmark, Italy, the Netherlands and other countries regulations: Under certain circumstances, the annual financial statements prepared by the company in addition to the historical cost reflects the value of fixed assets other than shown by the assessment of the need to put on the market value of fixed assets, in order to protect the interests of investors . Our asset appraisal industry in the reform and opening up and the process of establishing a socialist market economy, the rise of its impetus from the reform of state-owned assets management system, and in order to prevent the loss of state assets and determined that the fair value of the property transfer. September 1989, the State-owned Assets Administration formally promulgated the "Provisions on state-owned assets at the time of change of ownership of assets must be assessed", marking the birth of asset appraisal industry. Asset appraisal industry in safeguarding the legitimate rights and interests of all types of assets property rights and promote the strategic reorganization of state-owned economy, promote the formation and development of a diversified economic structure, and ensure the market economy order, played an important role.

Problems of Our Asset Appraisal Industry. Asset valuation under the market economy is a very important part, it is the price determined on the basis of corporate mergers and acquisitions. At present, China's asset valuation is still in its infancy, many practices are not standardized, resulting in distortion of asset assessment, contrary to the corporate merger and reorganization of the 
principle of equal value, not only reduces the efficiency of the market order, but also the huge loss of assets.

Asset appraisal industry professionals often feel unable to follow the asset assessment activities, in accordance with the law is difficult to embarrassment. First "People's Republic of China CPV Law" and "Asset valuation method" delay in the introduction, resulting in asset evaluation department in trouble everywhere and qualifications among separatist difficult to be effectively addressed. Secondly, the relevant government departments had to regulate asset valuation activity released some administrative rules and regulations, but because they are poorly designed or difficult to operate, or because of the passage of time and need to be amended, or the interests of each other due to a conflict between departments, in When the actual practice difficult to implement. Finally, due to the presence of construction defects in the law, so CPV industry compared with the CPA and the legal profession, the development of relatively tortuous and slow, several public opinion has become of particular concern to socially vulnerable sectors.

\section{Improve Corporate Mergers and Acquisitions in the Asset Valuation}

Strengthen the supervision of inter-mediary, we must proceed from China's specific national conditions, drawing on the successful experience of developed market economies and the regulatory agency practices, to learn the lessons of its failure to take various measures to carry out a comprehensive way.

Healthy development of asset evaluation industry is inseparable from the pioneering theories, the problem of the current asset assessment encountered deeper point of view and theoretical studies are lagging and theoretical system is not perfect correlation. So, in an effort to promote the advancement of practical work at the same time, we must attach great importance to theoretical research. At present, it should be developed as soon as possible, "People's Republic of China CPV Law" and "Asset Assessment Act," which included the two basic laws of schedule as soon as possible, and introduce practical operability has a high asset valuation in line with China's national conditions series of criteria and guidelines and other related laws and regulations, in order to meet the urgent need to develop the current assessment of the industry. Then, and then explore the experience in practice, and further amendments.

The prevailing rules of the international community is to evaluate the report positioned as advisory report, but because of China's specific national conditions, assets evaluation in our country there is a forensic function, under certain premise can also be used as the value basis for financial data to be adjusted. Dual identity assess the industry in the development process so that it seems contradictory, many constraints.

Achieve "multi-division merger" as soon as possible is one of the important things to save our assessment industry needs to do. The best way should be to assess the various qualifications into a unified organization, unified external communications and internal management, if necessary, can be further subdivided into different groups in the organization, each in charge of different areas and professional groups work. In some assessment industry is so relatively perfect area, such as the Hong Kong Institute of Surveyors on the nature of work in different segments of four different organizations. Ministry of Finance on December 10, 2003 promulgated the "strengthen and standardize the assessment on industry management advice" that read: our various industry associations should be independent and voluntary trade association established to assess joint conference system. At present, China should establish a joint conference system as soon as possible to assess trade associations, in order to improve and strengthen communication between the Association of the assessment, coordination and cooperation. Joint Meeting will be primarily responsible for research observations and recommendations of the assessment industry reform and development, study and propose standardized assessment practitioners practice of ethical guidelines, coordination of professional assessment practice guidelines and practice rules, laws and regulations involved in the assessment industry research drafting etc., for the assessment of long-term development of China's industry has important significance. 
Mergers and acquisitions in the asset valuation often the reason why there is a problem, a large part of the reason is the right and duty to assess agency does not match the cost of corruption involved in low and high income. China Securities Regulatory Commission as punishment for non-compliance assessment bodies, is limited to a warning, confiscation of illegal income, fines and revocation of the person directly responsible for qualification, the most severe but also revoke the license. Compared with the assessment agencies and profits obtained by the requester, such punishment is clearly lighter, do not act as a deterrent.

A large number of mergers and acquisitions category evaluation case revealed problems show: the current capacity of the domestic professional evaluators in the evaluation of intangible assets, and other aspects of business valuation is weak, and they may choose the assessment method is too casual, select the relevant parameters such phenomena are too subjective, seriously affecting the quality of evaluations. Therefore, we must strengthen the assessment of professional quality. It includes the following ways: (1) The value can now get into the practice of written examination and interview method only pass the examination and to consider an appropriate increase in CPV exam applicants threshold. (2) Increase the content evaluation of intangible assets, business valuation and other aspects of the content of the examination, and further improve the knowledge structure assessment professionals. (3) Drawing on the CPA exam management experience, increase public value examination disciplinary punishment, will help the first step off of good talent. (4) To further strengthen the follow-up education. Can refer to foreign experience, the member into the general membership, a senior member and a Fellow of three levels, according to the practice situation and practice levels were identified, namely training.

Many "false restructuring", "make up the numbers to assess" the case can be seen, the rating agencies for their own interests, and the requester collusion, manipulation of the appraised price, often less than the true role of mergers and acquisitions, but also serious damage to the small the interests of shareholders. Strengthening Professional Ethics evaluate employees comply with the assessment criteria are valued, the key to ensuring the quality of the assessment. Good work ethic can guarantee appraisers always provide high-quality, professional services, but also to the government, customers and the general public with a measure to assess the quality of the scale, maintaining appraiser, the interests of customers and the public. Strengthen the building of professional ethics must be active in asset appraisal industry liability insurance, liability risk assessment and effective control, eliminating assessment practitioners worries.

\section{Conclusion}

With the rapid development of market economy, mergers and acquisitions activity of enterprises becomes more active, more diverse and the country's asset evaluation industry has put forward higher requirements. After ten years of development, our asset appraisal industry has made some achievements, but more exposed many problems, many problems are deep-seated, structural and systemic. The development of any industry is not easy, our asset appraisal industry is at a crossroads, need a change, we need to continue to improve in the exploration of the theory and practice of learning among. With the full integration of asset evaluation industry, and learn from the advanced experience, its function will continue to be improved and continue to enhance the competitiveness of the industry, practice standards and service quality. It will continue to improve the socialist market economy and play increasingly important role.

\section{References}

[1] China Appraisal Society Beijing International Assessment Forum Proceedings Beijing: China Appraisal Society, 2000.

[2] Lu Xiaoling, Shen Ying. Out of the Debt Predicament Choices Beijing: Economic Science Press, 1999. 
[3] Institute of Financial and Commercial Bank of China State-Owned Enterprise Restructuring and Bank Asset Preservation Beijing: Economic Science Press, 1998.

[4] Guan Jing. Property, Mergers and Acquisitions of the Theory and Operation of Beijing: Economic Science Press, 1999.

[5] Zhu Zhigang. State Capital Quality Perspective and Strategic Restructuring. Beijing: Economic Science Press, 1999. 